\title{
Generating GPS activity spaces that shed light upon the mobility habits of older adults: a descriptive analysis
}

\author{
Jana A Hirsch ${ }^{1,2}$, Meghan Winters ${ }^{3 *}$, Philippa Clarke ${ }^{4}$ and Heather McKay ${ }^{5}$
}

\begin{abstract}
Background: Measuring mobility is critical for understanding neighborhood influences on older adults' health and functioning. Global Positioning Systems (GPS) may represent an important opportunity to measure, describe, and compare mobility patterns in older adults.

Methods: We generated three types of activity spaces (Standard Deviation Ellipse, Minimum Convex Polygon, Daily Path Area) using GPS data from 95 older adults in Vancouver, Canada. Calculated activity space areas and compactness were compared across sociodemographic and resource characteristics.

Results: Area measures derived from the three different approaches to developing activity spaces were highly correlated. Participants who were younger, lived in less walkable neighborhoods, had a valid driver's license, had access to a vehicle, or had physical support to go outside of their homes had larger activity spaces. Mobility space compactness measures also differed by sociodemographic and resource characteristics.

Conclusions: This research extends the literature by demonstrating that GPS tracking can be used as a valuable tool to better understand the geographic mobility patterns of older adults. This study informs potential ways to maintain older adult independence by identifying factors that influence geographic mobility.
\end{abstract}

Keywords: Global positioning systems (GPS), Geographic information systems (GIS), Activity space, Mobility, Neighborhood attributes, Older adults

\section{Background}

Mobility is defined as the "ability to move oneself (either independently or by using assistive devices or transportation) within environments that expand from one's home to one's neighborhood and regions beyond" [1]. Mobility is key to older adults leading active, healthy, independent lives [2] and is central to them conducting commercial, cultural, and social activities [3-5]. Older adults' well-being and quality of life are also closely linked to their mobility [5-8]. The demographic shift toward an aging population is unprecedented in western society and demands novel solutions that evaluate and promote the mobility of older adults. These solutions may be embedded within transportation systems and planning [9-13].

\footnotetext{
* Correspondence: mwinters@sfu.ca

${ }^{3}$ Faculty of Health Sciences, Simon Fraser University, 8888 University Drive, Burnaby, British Columbia V5A 1S6, Canada

Full list of author information is available at the end of the article
}

It is essential to identify effective tools to describe older adult mobility so as to better understand the influence of neighborhood on their health and mobility [14]. "Lifespace" is a frequently used measure of older adult mobility [15-17]. This self-reported measure of the extent of recent travel (using thresholds such as: within the home, into the local neighborhood, or beyond) was positively associated with diminished cognitive decline and Alzheimer's Disease $[18,19]$, lower risk of both death [20] and becoming more frail [21]. Older age, being female, and having physical limitations have been associated with smaller life-spaces, as is having had a stroke, high depressive symptoms, and being obese $[22,23]$. Higher education, better lower extremity function and muscle strength were associated larger life-spaces [22,23]. Importantly, the ability to drive plays a key role in the mobility of older adults as captured using life-space measures [23-26]. 
Global Positioning Systems (GPS) technology may provide a means to calculate geographic range as a measure of mobility. GPS has been used to objectively characterize life-space [27-32] and also to detect outside physical activity [33]. Most research using GPS for older adult mobility comes from one study-the Senior Tracking (SenTra) project, based in Germany and Israel. SenTra used GPS points or metrics of out-of-home behaviors (e.g. number of visited places, time spent outside the home, and distance traveled from home) to assess mobility patterns in a sample of older adults who were cognitively impaired or had Alzheimer's disease, and compared this clinical group with community-dwelling older adults [34-47]. It may not be possible to generalize outcomes from SenTra across geographically and culturally diverse settings, or with older adults who are independent and able to make their own travel decisions. Therefore, there is a need to investigate GPS applications in community-dwelling older adults in the North American context, given the limited knowledge base on measurement approaches to define the geographic patterns (i.e. shape) and extent (i.e. size) of older adult mobility in this population. Additionally, the potential to characterize older adults' geographic extent or pattern was not explored in any of these studies, leaving questions about where older adults travel.

To represent daily mobility, neighborhood studies of physical activity have used GPS-based "activity spaces" as an individual-based measure of spatial behavior [48-52]. Activity spaces differ from the life-space measure, in that they focus on neighborhood (out of home) behavior only, rather than mobility both within and beyond the home. Additionally, with the exception of recent efforts to incorporate GPS [27-32], the majority of life-space studies are based on self-reported travel extents (within the home, into the local neighborhood, or beyond), not spatiallylocated travel data. Thus, the expansion of activity spaces to the investigation of older adult mobility will give additional insight into the community factors and resources that shape neighborhood activity. It is hypothesized that activity spaces may vary in size and shape across different populations, such as those with low incomes or different age groups [50,53]. To date the utility of GPS to measure, describe, and compare mobility patterns in older adults has not been fully explored. Previous work proposed using a "mobility envelope", the length of the outer perimeter of spatial excursions made by individuals, as an outcome measure for mobility studies in older adults [54]. By integrating various metrics of geographic extent from activity space studies, the mobility envelope concept could be advanced. For example, additional metrics evaluating different dimensions of individuals' geographic scope may be useful for understanding mobility. In particular, in urban planning the shape or "compactness" of activity spaces is a metric of how circular a polygon is and is a concept thought to illustrate the capacity of neighborhoods to provide opportunities to "live, work, shop, and socialize at the local scale" [53]. Specifically, compactness has been shown to vary across different travel modes [55]. However, comparisons of compactness among different individuals (and within a particular type of activity space) may reveal important information on the role of driving in older adult mobility.

Therefore our objectives are twofold: to create and compare different types of geographic activity spaces for community dwelling older adults, so as to clarify the extent and pattern of their mobility; and then within each activity space approach, to assess individual sociodemographic and resource characteristics that are associated with larger (or smaller) or more (or less) compact activity spaces. We hypothesize that the size and shape of activity spaces will vary by the approach used to create them. Within each activity space type we hypothesize that participants who are younger, healthier, and with better access to transportation (driving or material resources for going outside) will have larger activity spaces. Furthermore, we hypothesize that those who drive less will have more compact activity spaces, and also that participants who live in more walkable neighborhoods will have more compact activity spaces, since amenities may be closer to home.

\section{Results}

Participants had GPS data for a mean of 3.5 days (standard deviation (SD) 1.7 days; median 3.0 interquartile range (IQR) 3.0) with a mean of 14656.3 GPS points (SD 10232.8; median 12132, IQR 12401). Participants traveled between 1 and 12 trips each day they were tracked, with a mean of 13.2 total trips (SD 7.8; median 13.0, IQR 12.0) per participant.

The areas derived from the three different approaches to developing activity spaces were highly associated; correlation coefficients ranged from $\rho=0.96$ (Standard Deviation Ellipse (SDE) area vs Daily Path Area (DPA) area) to $\rho=0.98$ (Minimum Convex Polygon (MCP) area vs DPA area and MCP area vs SDE area). However, values for compactness varied greatly between approaches; although compactness values derived from MCP and SDE approaches were highly correlated $(\rho=0.82, p<0.0001)$, compactness values derived using DPA were not correlated with either MCP or SDE approaches $(\rho=0.07 p=0.49$ and $\rho=-0.01$ $\mathrm{p}=0.92$, respectively). Activity spaces were larger than the traditional buffers (200-meters or 1/8-mile; 400 -meters or $1 / 4$-mile; 800 -meters or $1 / 2$-mile) used for neighborhood research (Figure 1).

In terms of size, DPA generated the smallest and MCP the largest (Table 1) activity space areas. Patterns for activity space area by sociodemographic group and resource characteristics were consistent across approaches. 


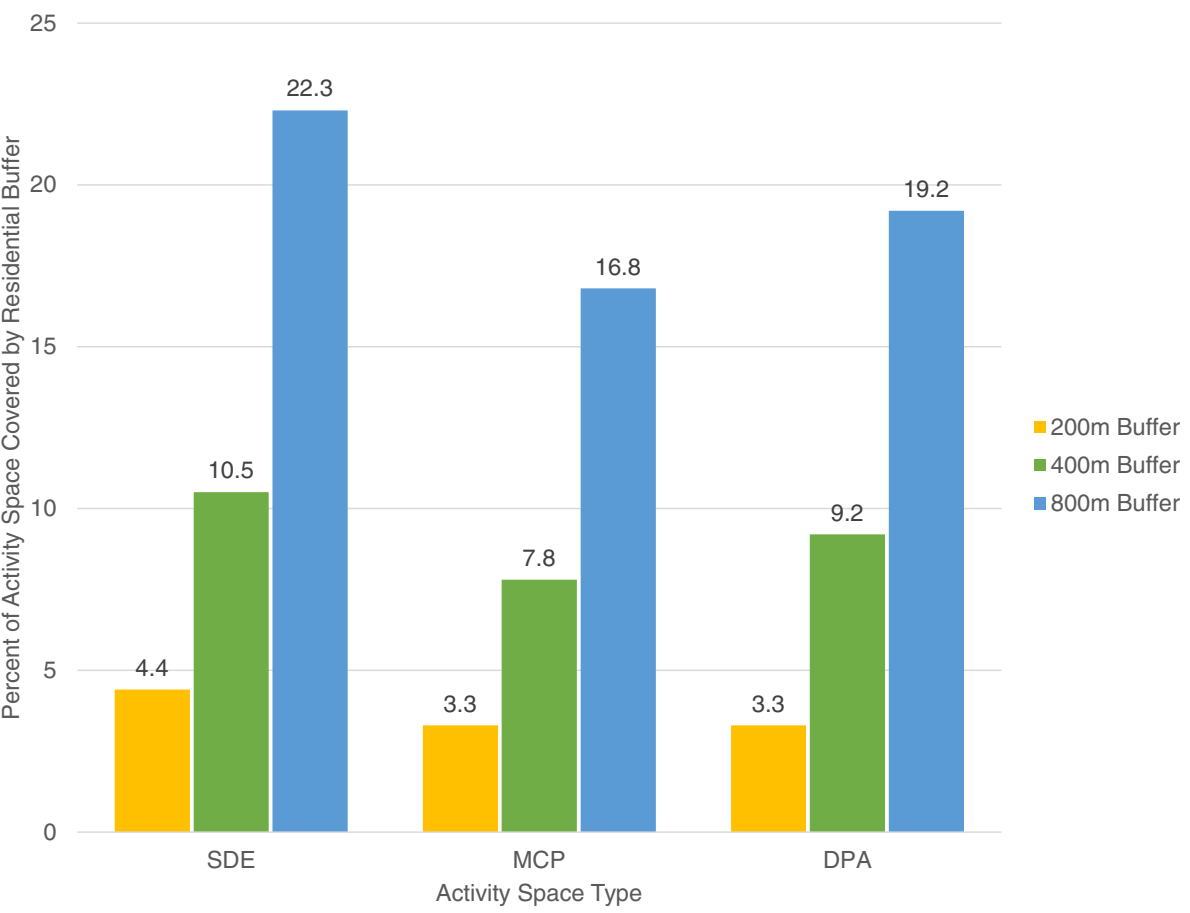

Figure 1 Percentage of activity space covered by traditional residential buffers (200-meter, 400-meter, 800-meter).

Activity space areas were generally larger for younger participants, those in less walkable neighborhoods, those with valid driver's licenses, those with access to a vehicle in the past 7 days, and those with physical support to go outside.

Compactness values generated using SDE and MCP approaches were much higher than were DPA-generated values (Table 2), signifying more circular shapes by these approaches. Men had more compact SDE and evidence of more compact MCP, compared with women. Compactness values generated using SDE and MCP approaches were higher in areas with lower walkability (as measured by Walk Score), while compactness assessed using the DPA approach was higher in areas of higher walkability. Participants who had a valid driver's license, and had access to a vehicle in the past 7 days had less compact values generated using the DPA approach. Participants who very much liked to walk outside had lower values for compactness if generated using SDE or MCP approaches.

Log-linear models demonstrated that participants who lived in less walkable neighborhoods, who had access to a vehicle or who had physical support to go outside had significantly larger activity spaces (Table 3 ). Linear models demonstrated limited associations between sociodemographic or resource characteristics and compactness of activity space. Only three sociodemographic or resource characteristics were associated with compactness of activity spaces: living in walkable neighborhoods, liking to walk outside, and access to a vehicle. Using the SDE and MCP approaches, participants who lived in somewhat walkable neighborhoods had higher values for compactness and those who reported they very much like to walk outside had less compact activity spaces. Participants living in less walkable neighborhoods and with access to a vehicle had less compact DPA-generated activity spaces.

\section{Discussion}

This research is one of the first studies to utilize GPS tracking to create activity spaces as a means to assess older adult mobility. We extend the literature by demonstrating that GPS tracking can be used to create three different types of activity spaces as a valuable tools to better understand the geographic mobility patterns of older adults. Not surprisingly, older adults deemed most mobile based on their age, the walkability of their neighborhoods, and whether or not they drove, had the largest activity spaces. The trends in activity space areas were not different, regardless of what approach was used to generate them. However, shape of activity spaces (measured as compactness) varied by approach.

Walking and cycling trips are often extend beyond traditional buffer sizes ( 1 mile, $1 / 2$ mile) used to represent neighborhoods where older adults live [56]. We demonstrated that GPS may enable a more precise way to operationalize neighborhoods than residential buffers or administrative units [51,57-62] as it better captures the locations individuals actually visit rather than a presumed neighborhood 
Table 1 GPS-based activity space areas of Walk The Talk Study participants $(n=95)$ by sociodemographic group and resource characteristics

\begin{tabular}{|c|c|c|c|c|c|c|c|}
\hline \multirow[t]{2}{*}{ Sociodemographic group } & \multirow[t]{2}{*}{$\mathrm{n}$} & \multicolumn{2}{|c|}{ SDE area (in hectares) } & \multicolumn{2}{|c|}{ MCP area (in hectares) } & \multicolumn{2}{|c|}{ DPA area (in hectares) } \\
\hline & & Median (IQR) & $p^{\mathrm{a}}$ & Median (IQR) & $p^{\mathrm{a}}$ & Median (IQR) & $p^{a}$ \\
\hline$\overline{\text { All }}$ & 95 & $1121.9(3900.8)$ & & $1753.6(7097.9)$ & & $837.2(1389.1)$ & \\
\hline Sex & & & 0.3467 & & 0.4616 & & 0.6060 \\
\hline Female & 63 & $1183.8(4903.2)$ & & $1753.6(7256.0)$ & & $837.2(1603.6)$ & \\
\hline Male & 32 & $972.7(2355.6)$ & & $1752.6(4974.1)$ & & $839.8(1147.7)$ & \\
\hline Age (years) & & & 0.0289 & & 0.0617 & & 0.1293 \\
\hline $65-69$ & 26 & $3071.1(8827.8)$ & & $4764.5(12583.2)$ & & $1448.6(1588.1)$ & \\
\hline $70-74$ & 29 & $1909.6(3362.5)$ & & $1952.4(6744.7)$ & & $958.4(1150.5)$ & \\
\hline $75-79$ & 26 & $680.5(1423.0)$ & & $1031.3(2325.3)$ & & $566.5(937.2)$ & \\
\hline $80+$ & 14 & $483.2(1397.3)$ & & $791.8(2624.7)$ & & $532.6(548.3)$ & \\
\hline Race & & & 0.2727 & & 0.3351 & & 0.4617 \\
\hline Non-white & 18 & $693.5(5189.3)$ & & $1163.0(5545.7)$ & & $786.4(1486.7)$ & \\
\hline White & 77 & 1379.6 (3539.9) & & $1896.0(6854.3)$ & & $837.2(1353.0)$ & \\
\hline Education & & & 0.8895 & & 0.7534 & & 0.8814 \\
\hline Secondary school or less & 26 & $982.5(2522.6)$ & & $1456.0(2396.1)$ & & $846.1(838.7)$ & \\
\hline Some or completed trade/technical school or college & 36 & $1652.6(7491.1)$ & & $2837.4(9796.7)$ & & $949.9(1853.6)$ & \\
\hline Some university or higher & 33 & $887.0(3896.6)$ & & $1569.1(5537.3)$ & & $837.2(1192.6)$ & \\
\hline Marital status & & & 0.5785 & & 0.8197 & & 0.8308 \\
\hline Not married & 88 & $1160.3(3735.0)$ & & $1817.2(7119.1)$ & & $833.8(1489.2)$ & \\
\hline Married & 7 & $616.6(5038.3)$ & & $1317.0(4865.3)$ & & $1035.2(1085.0)$ & \\
\hline Living with someone else & & & 0.7248 & & 0.9715 & & 0.7171 \\
\hline No & 80 & $1129.3(3764.0)$ & & $1731.2(7124.3)$ & & $781.8(1600.1)$ & \\
\hline Yes & 15 & $942.8(4024.0)$ & & $2777.3(4865.3)$ & & $1035.2(1079.6)$ & \\
\hline Dog ownership & & & 0.5570 & & 0.8752 & & 0.9120 \\
\hline No & 84 & $1160.3(4036.8)$ & & $1794.8(7134.7)$ & & $830.2(1396.0)$ & \\
\hline Yes & 11 & $887.0(2538.0)$ & & $1753.6(5488.9)$ & & $837.2(1280.9)$ & \\
\hline Walkability $^{\mathrm{b}}$ & & & 0.0182 & & 0.0096 & & 0.0116 \\
\hline Car dependent (0-49) & 19 & $3018.3(16101.5)$ & & $7982.4(23676.8)$ & & $2037.2(2720.9)$ & \\
\hline Somewhat walkable (50-69) & 24 & $1194.6(2898.6)$ & & $1888.4(6268.4)$ & & $1037.9(1355.4)$ & \\
\hline Very walkable (70-89) & 27 & $1614.0(4074.9)$ & & $2243.0(7064.9)$ & & $751.0(1268.4)$ & \\
\hline Walker's paradise (90-100) & 25 & $605.4(1830.6)$ & & $1008.9(2615.6)$ & & $542.4(773.5)$ & \\
\hline Length of time in neighborhood & & & 0.4415 & & 0.6514 & & 0.7263 \\
\hline$\leq 2$ years & 27 & $1593.0(4628.6)$ & & $1912.1(7060.9)$ & & $958.4(1592.3)$ & \\
\hline Between 2 and up to 6 years & 28 & $839.8(5695.7)$ & & $1535.3(9962.9)$ & & $794.1(1476.8)$ & \\
\hline Between 6 and up to 9 years & 17 & $942.8(3631.5)$ & & $2243.0(6116.3)$ & & $752.4(1498.6)$ & \\
\hline$>9$ years & 23 & $770.4(3672.6)$ & & $1096.2(7321.2)$ & & $701.9(1310.5)$ & \\
\hline Valid driver's license & & & 0.0624 & & 0.0501 & & 0.0309 \\
\hline No & 23 & $617.6(2543.3)$ & & $1053.7(3075.3)$ & & $544.5(1013.9)$ & \\
\hline Yes & 72 & $1218.1(4266.3)$ & & $1904.0(6986.1)$ & & $942.5(1529.9)$ & \\
\hline Access to a vehicle & & & 0.0061 & & 0.0027 & & 0.0010 \\
\hline No & 37 & $617.6(2002.8)$ & & $1008.9(2928.5)$ & & $504.7(900.9)$ & \\
\hline Yes & 56 & 1613.7 (4678.6) & & $2501.9(7009.7)$ & & 997.4 (1511.6) & \\
\hline
\end{tabular}




\begin{tabular}{|c|c|c|c|c|c|c|c|}
\hline Social support/companionship to go outside & & & 0.5381 & & 0.3413 & & 0.2613 \\
\hline No & 44 & $982.5(3446.7)$ & & $1456.8(5476.1)$ & & $741.0(1265.3)$ & \\
\hline Yes & 51 & $1183.8(3789.5)$ & & $1896.0(7054.8)$ & & $958.4(1532.4)$ & \\
\hline Physical support to go outside & & & 0.0537 & & 0.0405 & & 0.0510 \\
\hline No & 51 & $887.0(2731.0)$ & & $1305.4(3766.4)$ & & $695.0(893.0)$ & \\
\hline Yes & 44 & $1942.6(8296.2)$ & & $2937.3(11791.8)$ & & $1047.8(1757.7)$ & \\
\hline Like to walk outside ${ }^{c}$ & & & 0.8864 & & 0.9967 & & 0.8929 \\
\hline Less than very much & 28 & $813.5(4273.7)$ & & $1222.3(6828.0)$ & & $741.7(1469.7)$ & \\
\hline Very much & 67 & $1136.8(3683.4)$ & & $1896.0(7124.4)$ & & $854.9(1402.9)$ & \\
\hline Confidence walking outside $^{c}$ & & & 0.6580 & & 0.7116 & & 0.8444 \\
\hline Less than very much & 20 & $684.3(6950.3)$ & & $1168.8(11618.3)$ & & 716.5 (1919.9) & \\
\hline Very much & 75 & $1183.8(3482.5)$ & & $1896.0(6947.3)$ & & $849.2(1355.9)$ & \\
\hline Falls in past 6 months & & & 0.8301 & & 0.8444 & & 0.9164 \\
\hline No & 75 & $1252.4(3900.8)$ & & $1952.4(7118.7)$ & & $854.9(1389.1)$ & \\
\hline Yes & 20 & $1004.4(3384.5)$ & & $1596.8(6563.9)$ & & $824.3(1407.8)$ & \\
\hline Use of a mobility aid for walking & & & 0.5248 & & 0.5185 & & 0.3691 \\
\hline No & 78 & $1152.8(3596.6)$ & & $1888.4(7125.3)$ & & $852.1(1421.1)$ & \\
\hline Yes & 17 & $1002.7(6047.0)$ & & $1241.5(9690.6)$ & & $752.4(1556.3)$ & \\
\hline
\end{tabular}

Abbreviations: Interquartile range (IQR), Standard Deviation Ellipse using one standard deviation (SDE), Minimum Convex Polygon (MCP), Daily Path Area using a 200-meter buffer (DPA).

${ }^{a}$ p-value from Kruskal-Wallis non-parametric one-way Analysis of Variance (ANOVA) or Wilcoxon Rank Sum test across sociodemographic and resource categories. ${ }^{\mathrm{b}}$ Measured by Street Smart Walk Score for home address.

'Less than very much (1-4 on a 5 -point scale); Very much (5 on a 5 -point scale).

boundary. GPS has recently become a more popular option for measuring neighborhood exposure and context in health studies [33,50,63-67]. As the analytic approaches to GPS data develop, this technology may become a powerful tool to accurately and precisely describe people's interactions with geographic space, including older adult mobility. It is possible that different types of activity spaces may be more appropriate depending on the application or the research question being addressed. Since the MCPgenerated activity space is bounded by the outermost GPS points, it captures the envelope of the extreme extent of travel and thus may include large geographic areas that are not visited by, or important to, an individual [68]. In contrast, SDE-generated spaces may be more useful if one wishes to assess the direction and general shape of a person's travel area, without introducing potential error introduced by using geographically distant points. In addition, SDE approaches may indicate the frequency that an individual visits a geographic area as more points are generated in that location - this 'pulls' the SDE-generated activity space toward that more often visited geographic area. However, since SDE-generated activity spaces are by definition ellipse shaped, they may also capture a substantial area that an individual may not have visited. Finally, we recommend using DPA to generate an activity space if a research question is about the destinations participants pass in daily travel, as it relies solely on buffering the routes actually traveled.

The consistency of activity space area across the three different approaches aligns with a previous study that showed associations across MCP, SDE, and line-based buffers [52]. However, no previous studies assessed the shape (compactness) of GPS-derived activity spaces. In our study, patterns of compactness differed depending on the approach used to generate activity space. This signals the need to choose an approach to generating an activity space that is relevant to the research question being asked. Of interest, compactness generated using the SDE and MCP approach was higher when walkability was lower, whereas for DPAgenerated compactness was higher in neighborhoods with higher Walk Score. This finding may illustrate that participants in neighborhoods with lower walkability are clustering their trips to a nearby retail area. Thus, in neighborhoods with lower walkability the area of all three activity space types becomes larger, and the compactness of the SDE and MCP is higher. However, in this same scenario, DPA-generated activity spaces become more elongated, potentially with multiple trips heading in the same direction, which results in a less compact DPA-generated activity space. Our findings using DPA are consistent with work indicating that small and compact activity spaces increase the likelihood of walking and cycling [55]. 
Table 2 GPS-based activity space compactness of Walk The Talk Study participants $(\mathbf{n}=95)$ by sociodemographic group and resource characteristics

\begin{tabular}{|c|c|c|c|c|c|c|c|}
\hline \multirow[t]{2}{*}{ Sociodemographic group } & \multirow[t]{2}{*}{$\mathrm{n}$} & \multicolumn{2}{|c|}{ SDE compactness (0 to 1 ) } & \multicolumn{2}{|c|}{ MCP compactness ( 0 to 1 ) } & \multicolumn{2}{|c|}{ DPA compactness ( 0 to 1 ) } \\
\hline & & Mean (SD) & $p^{\mathrm{a}}$ & Mean (SD) & $p^{\mathrm{a}}$ & Mean (SD) & $p^{\mathrm{a}}$ \\
\hline All & 95 & $0.77(0.15)$ & & $0.75(0.11)$ & & $0.34(0.21)$ & \\
\hline Sex & & & 0.0506 & & 0.0919 & & 0.6597 \\
\hline Female & 63 & $0.75(0.15)$ & & $0.74(0.11)$ & & $0.33(0.21)$ & \\
\hline Male & 32 & $0.81(0.12)$ & & $0.77(0.09)$ & & $0.35(0.21)$ & \\
\hline Age (years) & & & 0.9822 & & 0.9412 & & 0.2115 \\
\hline $65-69$ & 26 & $0.77(0.14)$ & & $0.75(0.10)$ & & $0.29(0.21)$ & \\
\hline $70-74$ & 29 & $0.77(0.16)$ & & $0.74(0.12)$ & & $0.31(0.18)$ & \\
\hline $75-79$ & 26 & $0.77(0.15)$ & & $0.74(0.11)$ & & $0.40(0.23)$ & \\
\hline $80+$ & 14 & $0.79(0.13)$ & & $0.76(0.09)$ & & $0.38(0.21)$ & \\
\hline Race & & & 0.3052 & & 0.3293 & & 0.1429 \\
\hline Non-white & 18 & $0.74(0.12)$ & & $0.73(0.11)$ & & $0.41(0.27)$ & \\
\hline White & 77 & $0.78(0.15)$ & & $0.75(0.11)$ & & $0.33(0.19)$ & \\
\hline Education & & & 0.1546 & & 0.0172 & & 0.4758 \\
\hline Secondary school or less & 26 & $0.77(0.16)$ & & $0.74(0.11)$ & & $0.30(0.11)$ & \\
\hline Some or completed trade/technical school or college & 36 & $0.81(0.12)$ & & $0.79(0.08)$ & & $0.37(0.27)$ & \\
\hline Some university or higher & 33 & $0.74(0.16)$ & & $0.71(0.12)$ & & $0.34(0.19)$ & \\
\hline Marital status & & & 0.8909 & & 0.4912 & & 0.9096 \\
\hline Not married & 88 & $0.77(0.15)$ & & $0.75(0.11)$ & & $0.34(0.21)$ & \\
\hline Married & 7 & $0.78(0.15)$ & & $0.78(0.10)$ & & $0.35(0.25)$ & \\
\hline Living with someone else & & & 0.8379 & & 0.5398 & & 0.8590 \\
\hline No & 80 & $0.77(0.14)$ & & $0.75(0.11)$ & & $0.34(0.21)$ & \\
\hline Yes & 15 & $0.77(0.16)$ & & $0.76(0.10)$ & & $0.33(0.21)$ & \\
\hline Dog Ownership & & & 0.9119 & & 0.7896 & & 0.6049 \\
\hline No & 84 & $0.77(0.14)$ & & $0.75(0.11)$ & & $0.34(0.20)$ & \\
\hline Yes & 11 & $0.77(0.19)$ & & $0.76(0.12)$ & & $0.37(0.29)$ & \\
\hline Walkability ${ }^{\mathrm{b}}$ & & & 0.0721 & & 0.0325 & & 0.0244 \\
\hline Car dependent (0-49) & 19 & $0.77(0.13)$ & & $0.73(0.11)$ & & $0.24(0.14)$ & \\
\hline Somewhat walkable (50-69) & 24 & $0.83(0.13)$ & & $0.79(0.08)$ & & $0.31(0.18)$ & \\
\hline Very walkable (70-89) & 27 & $0.77(0.14)$ & & $0.77(0.09)$ & & $0.36(0.23)$ & \\
\hline Walker's paradise (90-100) & 25 & $0.72(0.16)$ & & $0.70(0.13)$ & & $0.42(0.23)$ & \\
\hline Length of time in neighborhood & & & 0.0659 & & 0.4341 & & 0.5547 \\
\hline$\leq 2$ years & 27 & $0.77(0.15)$ & & $0.75(0.10)$ & & $0.29(0.18)$ & \\
\hline Between 2 and up to 6 years & 28 & $0.76(0.12)$ & & $0.74(0.11)$ & & $0.36(0.24)$ & \\
\hline Between 6 and up to 9 years & 17 & $0.71(0.16)$ & & $0.72(0.11)$ & & $0.34(0.21)$ & \\
\hline$>9$ years & 23 & $0.83(0.14)$ & & $0.77(0.11)$ & & $0.37(0.21)$ & \\
\hline Valid driver's license & & & 0.2126 & & 0.9521 & & 0.0175 \\
\hline No & 23 & $0.74(0.14)$ & & $0.75(0.10)$ & & $0.43(0.26)$ & \\
\hline Yes & 72 & $0.78(0.15)$ & & $0.75(0.11)$ & & $0.31(0.19)$ & \\
\hline Access to a vehicle & & & 0.5099 & & 0.7018 & & 0.0007 \\
\hline No & 37 & $0.76(0.15)$ & & $0.75(0.11)$ & & $0.43(0.25)$ & \\
\hline Yes & 56 & $0.78(0.14)$ & & $0.74(0.11)$ & & $0.28(0.16)$ & \\
\hline
\end{tabular}




\begin{tabular}{|c|c|c|c|c|c|c|c|}
\hline Social support/companionship to go outside & & & 0.5297 & & 0.9556 & & 0.5838 \\
\hline No & 44 & $0.78(0.15)$ & & $0.75(0.11)$ & & $0.35(0.21)$ & \\
\hline Yes & 51 & $0.76(0.14)$ & & $0.75(0.10)$ & & $0.33(0.21)$ & \\
\hline Physical support to go outside & & & 0.3954 & & 0.3574 & & 0.1288 \\
\hline No & 51 & $0.78(0.14)$ & & $0.76(0.10)$ & & $0.37(0.22)$ & \\
\hline Yes & 44 & $0.76(0.15)$ & & $0.74(0.11)$ & & $0.31(0.19)$ & \\
\hline Like to walk outside ${ }^{c}$ & & & 0.0021 & & 0.0037 & & 0.9144 \\
\hline Less than very much & 28 & $0.84(0.11)$ & & $0.80(0.08)$ & & $0.34(0.22)$ & \\
\hline Very much & 67 & $0.74(0.15)$ & & $0.73(0.11)$ & & $0.34(0.21)$ & \\
\hline Confidence walking outside ${ }^{c}$ & & & 0.8907 & & 0.7597 & & 0.4028 \\
\hline Less than very much & 20 & $0.78(0.13)$ & & $0.74(0.09)$ & & $0.38(0.26)$ & \\
\hline Very much & 75 & $0.77(0.15)$ & & $0.75(0.11)$ & & $0.33(0.19)$ & \\
\hline Falls in past 6 months & & & 0.8087 & & 0.7402 & & 0.7583 \\
\hline No & 75 & $0.77(0.15)$ & & $0.75(0.11)$ & & $0.34(0.21)$ & \\
\hline Yes & 20 & $0.77(0.15)$ & & $0.74(0.11)$ & & $0.33(0.20)$ & \\
\hline Use of a mobility aid for walking & & & 0.3118 & & 0.9095 & & 0.1527 \\
\hline No & 78 & $0.78(0.14)$ & & $0.75(0.11)$ & & $0.35(0.22)$ & \\
\hline Yes & 17 & $0.74(0.15)$ & & $0.75(0.11)$ & & $0.27(0.12)$ & \\
\hline
\end{tabular}

Abbreviations: Standard Deviation (SD), Standard Deviation Ellipse using one standard deviation (SDE), Minimum Convex Polygon (MCP), Daily Path Area using a 200-meter buffer (DPA).

ap-value from one-way Analysis of Variance (ANOVA) across sociodemographic and resource categories.

${ }^{b}$ Measured by Street Smart Walk Score for home address.

'Less than very much (1-4 on a 5-point scale); Very much (5 on a 5-point scale).

A number of factors surfaced as important to older adults' mobility. First, it is intuitive and supported by previous studies that an older adult's ability to drive will influence the size of their activity space [23-26], and that the activity space of older adult will be smaller compared with a younger person, on average [22]. Sex did not surface as a differentiating factor in our study, in contrast with previous reports that women had smaller activity spaces than did men [22,23]. However, as only one-third of our sample were men it is possible we lacked the statistical power to test this association. Second, when an older person is no longer able to drive, physical support to maintain mobility within the neighborhood becomes increasingly important. Given its apparent role in our study around encouraging older adults to travel within their neighborhoods, physical support may represent an effective intervention in future studies. Third, our results support previous findings - that neighborhood attributes (i.e. higher street connectivity, proximity to destinations, and traffic conditions, and parks) are associated with increased mobility among older adults [65,69-71]. Although seemingly counterintuitive at first glance, our finding that those living in higher walkability areas had smaller activity spaces could reflect closer proximity and access to amenities, and the use of different modes of transport. That is, highly walkable neighborhoods are more likely to have destinations that older people deem important, within easier walking access. As walking trips are often shorter than driving trips, this would reduce distance traveled to these destinations. However, this study cannot disentangle the competing and related concepts of walkability and car usage. On one hand, car usage was associated with larger activity spaces, potentially indicating greater mobility, yet walkability was associated with smaller spaces, potentially indicating that the local neighborhood environment is sufficient to fulfill daily activities and amenities. Future work creating activity spaces by mode or considering the distance traveled or frequency of trips within an activity space may help tease apart these complex and complementary elements of older adult mobility. All of these results are novel and in our view, are worth pursuing in future trials that evaluate different groups of older adults (we recruited older adults with low incomes) who reside across diverse built environment settings.

The life-space literature indicates that greater mobility is related to a wide range of favorable health outcomes [18-21]. This study indicates that larger activity spaces are associated with a number of different resources such as younger age, access to a vehicle, or physical support for going outside. One possibility is that the geographic mobility of individuals, as measured either in life-space or activity space, is in fact a proxy for personal resources. 
Table 3 Associations between sociodemographic groups, resource characteristics and GPS-based activity space area and compactness of Walk The Talk Study Participants $(\mathbf{n}=\mathbf{9 5})$

\begin{tabular}{|c|c|c|c|c|c|c|}
\hline & \multicolumn{3}{|c|}{ Area } & \multicolumn{3}{|c|}{ Compactness } \\
\hline & SDE & MCP & DPA & SDE & MCP & DPA \\
\hline & $\begin{array}{l}\text { Percent difference } \\
(95 \% \mathrm{CL})\end{array}$ & $\begin{array}{l}\text { Percent difference } \\
\quad(95 \% \mathrm{CL})\end{array}$ & $\begin{array}{l}\text { Percent difference } \\
(95 \% \mathrm{CL})\end{array}$ & $\begin{array}{l}\text { Mean difference } \\
\quad(95 \% \mathrm{CL})\end{array}$ & $\begin{array}{l}\text { Mean difference } \\
\quad(95 \% \mathrm{CL})\end{array}$ & $\begin{array}{l}\text { Mean difference } \\
\quad(95 \% \mathrm{CL})\end{array}$ \\
\hline Male & $-25.5(-69.8,83.6)$ & $-19.0(-66.6,96.6)$ & $-15.0(-47.3,37.2)$ & $0.03(-0.03,0.09)$ & $0.02(-0.02,0.07)$ & $0.02(-0.07,0.11)$ \\
\hline \multicolumn{7}{|l|}{ Age $\left(\right.$ years) ${ }^{a}$} \\
\hline $65-69$ & $125.8(-43.4,801.1)$ & $91.7(-50.8,647.7)$ & $46.1(-30.0,204.5)$ & $-0.07(-0.17,0.02)$ & $-0.04(-0.12,0.03)$ & $-0.08(-0.22,0.07)$ \\
\hline 70-74 & $71.1(-54.5,543.6)$ & $63.4(-55.6,501.1)$ & $30.8(-35.3,164.2)$ & $-0.06(-0.16,0.03)$ & $-0.05(-0.12,0.01)$ & $-0.06(-0.20,0.08)$ \\
\hline 75-79 & $-43.3(-85.0,114.5)$ & $-40.3(-83.9,120.7)$ & $-17.1(-59.1,68.0)$ & $-0.08(-0.17,0.02)$ & $-0.05(-0.12,0.01)$ & $0.03(-0.11,0.17)$ \\
\hline \multicolumn{7}{|l|}{ Education $^{a}$} \\
\hline $\begin{array}{l}\text { Some or completed trade/technical } \\
\text { school or college }\end{array}$ & $-15.2(-69.9,138.6)$ & $-4.5(-65.5,164.1)$ & $-1.9(-43.4,69.9)$ & $0.05(-0.02,0.12)$ & $0.06(0.00,0.11)$ & $0.05(-0.06,0.15)$ \\
\hline Some university or higher & $-5.6(-67.3,172.5)$ & $0.7(-64.5,185.7)$ & $5.1(-40.1,84.6)$ & $-0.01(-0.08,0.07)$ & $-0.02(-0.07,0.04)$ & $0.02(-0.09,0.13)$ \\
\hline \multicolumn{7}{|l|}{ Walkability ${ }^{a}$} \\
\hline Car Dependent (0-49) & $447.8(54.8,1838.7)$ & $525.2(80.4,2066.1)$ & $146.4(26.0,381.9)$ & $0.02(-0.07,0.11)$ & $0.01(-0.06,0.07)$ & $-0.16(-0.30,-0.03)$ \\
\hline Somewhat Walkable (50-69) & $213.7(0.6,877.8)$ & $237.7(10.4,932.7)$ & $102.3(10.6,269.9)$ & $0.09(0.01,0.17)$ & $0.07(0.01,0.13)$ & $-0.11(-0.23,0.01)$ \\
\hline Very Walkable (70-89) & $225.5(7.4,886.6)$ & $267.0(23.3,991.7)$ & $95.8(8.7,252.7)$ & $0.03(-0.05,0.11)$ & $0.05(-0.01,0.10)$ & $-0.09(-0.21,0.02)$ \\
\hline \multicolumn{7}{|l|}{ Length of time in Neighborhood ${ }^{a}$} \\
\hline Between 2 and up to 6 years & $--_{--{ }^{b}}$ & $-c^{b}$ & $-c^{b}$ & $0.00(-0.07,0.08)$ & $0.00(-0.06,0.05)$ & $0.04(-0.07,0.15)$ \\
\hline Between 6 and up to 9 years & $-c^{---b}$ & $----^{b}$ & $-c^{---b}$ & $-0.06(-0.15,0.03)$ & $-0.03(-0.09,0.03)$ & $-0.03(-0.16,0.10)$ \\
\hline$>9$ years & $-c^{b}$ & $-c^{b}$ & $-c^{b}$ & $0.06(-0.02,0.14)$ & $0.02(-0.04,0.07)$ & $0.03(-0.08,0.15)$ \\
\hline Have a valid driver's license & $46.4(-62.0,463.3)$ & $50.5(-60.0,466.4)$ & $17.7(-42.4,140.8)$ & $0.03(-0.07,0.12)$ & $-0.01(-0.08,0.06)$ & $-0.01(-0.15,0.13)$ \\
\hline Have access to a vehicle & $285.1(25.0,1085.9)$ & $304.4(33.8,1122.4)$ & $139.8(32.0,335.6)$ & $-0.02(-0.09,0.06)$ & $-0.02(-0.07,0.04)$ & $-0.16(-0.27,-0.04)$ \\
\hline Have physical support to go outside & $184.2(18.5,581.2)$ & $184.9(20.6,573.2)$ & $75.0(10.0,178.4)$ & $-0.03(-0.09,0.03)$ & $-0.02(-0.06,0.02)$ & $-0.08(-0.17,0.01)$ \\
\hline Like to walk outside very much & $-c^{b}$ & $-c^{b}$ & $-c^{b}$ & $-0.09(-0.15,-0.03)$ & $-0.06(-0.11,-0.02)$ & $-0.03(-0.12,0.06)$ \\
\hline
\end{tabular}

Abbreviations: Confidence Limits (CL), Standard Deviation Ellipse using one standard deviation (SDE), Minimum Convex Polygon (MCP), Daily Path Area using a 200-meter buffer (DPA). Bold values indicate estimates with $\mathrm{p}<0.05$.

with $\mathrm{p}<0.05$.
${ }^{2}$ Reference categories: $80+$ years old; secondary school or less; Walker's Paradise (Walk Score 90-100); living in neighborhood less than 2 years.

bot tested in models of area due to lack of significance in bivariate analysis. 
Additional work, examining changes in activity spaces as older adults transition through life changes (e.g. retirement, loss of a spouse, move to a more walkable neighborhood, driving cessation) may help to tease apart the complex connections between older adult resources, geographic mobility, and health outcomes.

\section{Strengths and limitations}

Our study has a number of strengths, including the characterization of a sample of older adults with low income, the examination of multiple methods to create activity space, and the provision of sufficient code to utilize these methods in other studies. We acknowledge that our study also has several limitations. It was not possible to draw strong conclusions given the relatively small and select sample, the cross-sectional design, and potential measurement error associated with self-reported characteristics and trip identification. Although older adults may experience some discomfort while wearing GPS devices [72], they were also highly compliant in wearing them. There was no clear association between any characteristics of older adults and their level of compliance with wearing GPS [73]. This study did not examine specific destinations or resources within activity spaces, although work building on this can illuminate factors that contribute to the capacity of neighborhoods to provide opportunities to older adults. Finally, bias associated with selective daily mobility may be a barrier to causal inference when using GPS to assess neighborhood exposure [74].

\section{Conclusion}

There are many different ways to represent geographic activity spaces where individuals travel to and spend their time. However, outcomes and interpretations may vary based on the approach used to generate an activity space. It is important to use an approach tailored to the needs of a specific research question and outcomes. Some factors we identified as important to geographic mobility of older adults may be used to inform interventions and to design policies that support older adults living and engaging independently with their community. Specifically, this work highlights the role of neighborhood walkability, driving patterns, and physical support to go outside as important factors in determining the size of older adult activity spaces. Identifying an approach that best captures the activity space of older adults may be useful for future work aimed at isolating features of the neighborhood environment that support older people 'aging in place' or informing interventions and policies that support older adults living independently in the community.

\section{Methods}

\section{Sample}

Participants were recruited to take part in Walk the Talk (WTT), a cross-sectional study $(\mathrm{n}=161)$ that evaluates the association between the built environment and the mobility and health of low-income older adults. Participants reside in eight cities in Metropolitan Vancouver (Burnaby, New Westminster, North Vancouver, Richmond, Surrey, Vancouver, West Vancouver, White Rock). Methods for WTT are described elsewhere [75], but briefly: WTT base population consists of 5806 households that receive a Shelter Aid for Elderly Renters (SAFER) rental subsidy from BC Housing, had a head of household aged $\geq 65$ years, and a telephone number on file with BC Housing (Figure 2). Households were sampled using a random stratified design, selecting 200 households from within each decile of walkability, measured using Street Smart Walk Score (www.walkscore.com) $\left(\mathrm{n}_{\text {total }}=2000\right)$, to ensure that participants were recruited across a range of built environments. Recruitment was done via telephone between January and February 2012. Individuals were excluded if they were diagnosed with dementia, left their home less than once in a typical week, were unable to understand or speak English, were unable to walk more than ten meters with or without a mobility aid (e.g. cane, walker), or were unable to participate in a mobility assessment involving a four meter walk. Measurement was conducted between March and May 2012. At the end of the measurement sessions, participants were instructed regarding wear of accelerometers and completion of travel diaries. A sub-group $(n=107)$ of participants received GPS and were instructed as to their use. The study was approved by the University of British Columbia's Clinical Research Ethics Board (certificate: H10-02913).

\section{Travel data}

Home locations were geocoded based on participant reported home address. Participants' travel patterns and physical activity was assessed using travel diaries, QStarz Datalogger BT-Q1000XT GPS sensors (Semsons, Arcadia, CA, USA; recording at $1 \mathrm{~s}$ ) and ActiGraph GT3X-Plus triaxial accelerometers (ActiGraph LLC, Fort Walton Beach, FL, USA), respectively, over the 7 days immediately following measurement sessions. For travel diaries, participants were instructed to record for each trip: start and end locations and times, reason for travel, mode of travel, and others who accompanied them. For the GPS sensors, the vibration sensor was activated to preserve memory and battery life; participants were not asked to charge devices so the data collection period was a function of battery life. GPS data were downloaded using the QStarz Data Viewer software. Of participants who were given GPS, $97.2 \%$ wore them and of these, we acquired valid data 


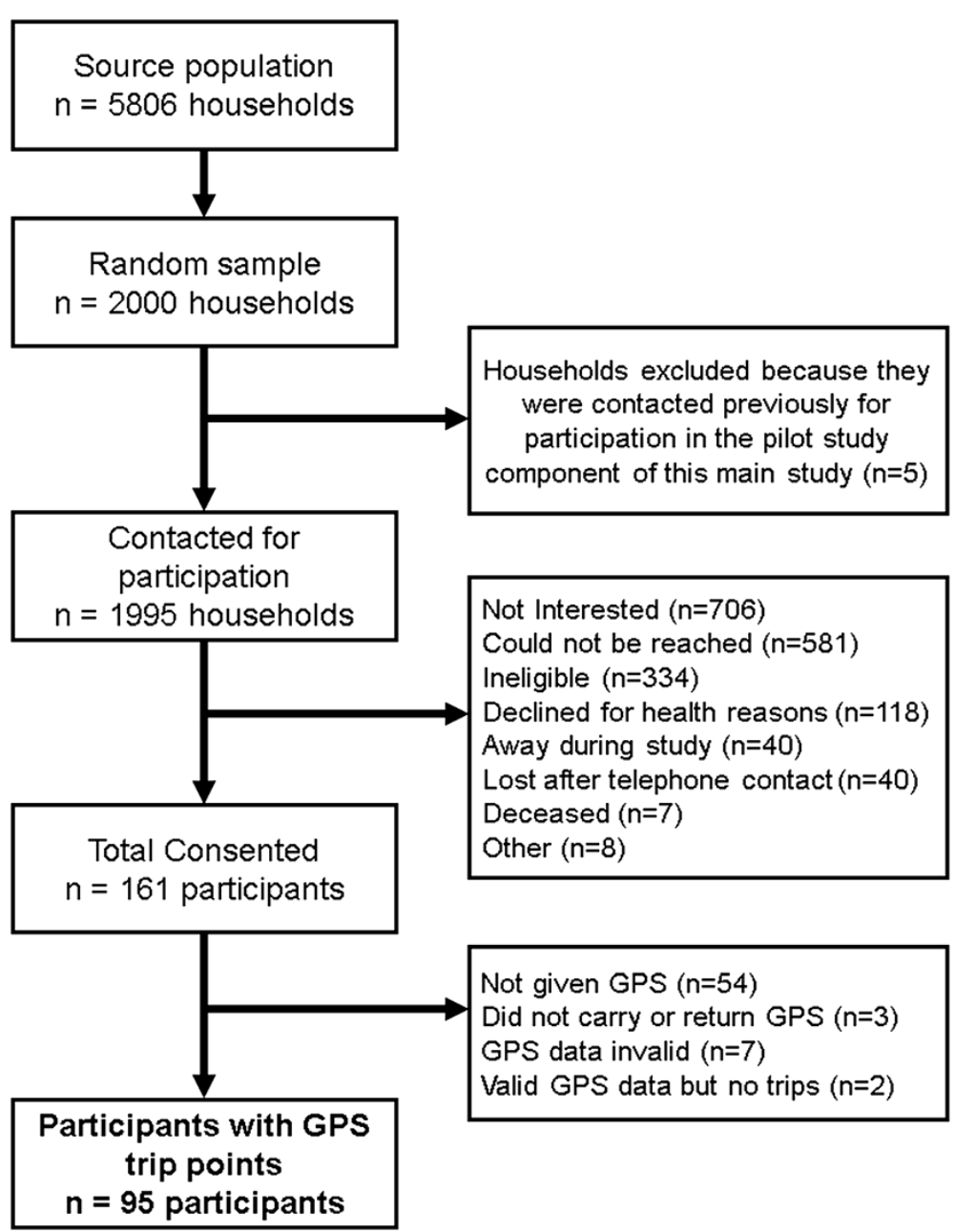

Figure 2 Walk The Talk (WTT) Participant recruitment and flow for GPS data. Source population comprised of households in our study area (Burnaby, New Westminster, North Vancouver, Richmond, Surrey, Vancouver, West Vancouver, White Rock) that receive a Shelter Aid for Elderly Renters rental subsidy from BC Housing, have a head of household aged greater than or equal to 65 years, and a telephone number on file with BC Housing. Participants were considered lost after telephone contact if they could not be reached again after expression of interest in study participation. GPS data was considered invalid if the unit was turned to the off position by the participant.

from 93.3\% ( $\mathrm{n}=97)$. For accelerometry, data were downloaded using the ActiLife software.

There is little consensus regarding best-practices for processing GPS data [76]. Previously, customized automated algorithms were used to identify destinations and trips from GPS data [77-80]. However, to capitalize on data acquired from travel diaries and to address broader questions related to multi-modal trips, we coded GPS data manually for this study, as has been done by our team [81] and others [82]. In brief, the 1-sec GPS data were first timealigned with accelerometer data and then processed using ArcGIS tracking analyst in concert with travel diaries to define the start and end points of trips based on trip speed, distance, duration, and accelerometry-defined activity level. Tracks had to be of $\geq 30 \mathrm{~s}$ in duration and $\geq 100 \mathrm{~m}$ distance to be considered a trip. Trip start was identified as the first GPS point outside of home or leaving the previous trips' destination location where speed $\geq 1 \mathrm{~km} / \mathrm{h}$ and distance $>0 \mathrm{~m}$ of movement. Changes from these criteria indicated trip stop time, allowing for pauses of $<5 \mathrm{~min}$ (e.g. at a stop light, bus stop). Two participants who did not $\log$ at least one out-of-home trip were excluded. Thus, the final sample size was $\mathrm{n}=95$ men and women who provided 333 days of recorded GPS data. We removed trips outside the metropolitan Vancouver area so as to represent participant movement within the region.

\section{GPS activity spaces}

There are a number of different ways, derived from geography and ecology, to analyze geographic behaviors using point data [67]. We analyzed trip-related GPS point data $(\mathrm{n}=1,392,347)$, aggregated by individual, using Python 2.7.2 (Python Software Foundation, www.python.org) and ArcPy for ArcGIS 10.1 (ESRI, Redlands, CA, USA). We 
represented activity space using three different approaches for each participant. They were; 1 . Standard Deviation Ellipse (SDE), 2. Minimum Convex Polygon (MCP), and 3. Daily Path Area (DPA) (Figure 3). SDE, a commonly used measures of activity space, measures the directional distribution of a series of points [49,50,52,62,83-85]. Similar to others $[49,50]$, we used a one-SDE that contains $68 \%$ of all GPS points. MCP, sometimes referred to as "home ranges", represents the smallest polygon that contains all GPS points $[62,86]$, with the outermost points serving as vertices [68]. DPA were adapted from previous literature $[50,52,87]$. We created them by buffering all of an individual's trips by 200-meters. We conducted sensitivity analyses on activity spaces with and without water. Areas were highly correlated (Spearman's $\rho>0.99, \mathrm{p}<0.0001$ ) and results were consistent across measures with and without water (not presented).

For the three activity space polygons we calculated two dimensions of activity space: 1. area (hectares) and 2 . compactness. Area and perimeter were generated using "Calculate Geometry" in ArcGIS. Compactness is a measure of how circular a polygon is; a value near 1 indicates the activity space is similar to a circle while a value near 0 indicates an elongated space, more closely resembling a line $[53,55]$. Compactness is calculated as the ratio of the perimeter of a circle with the same area to perimeter of the observed activity space. Compactness values may be related to the activity space approach (e.g., SDE would be expected to be more compact that DPA), however, within a given activity space type the comparison of compactness across individual sociodemographic and resource characteristics can highlight determinants of the shape, or local orientation, of travel.

We provide python code to create area and compactness across the three activity space measures, both with and without water, in the Additional file 1 that supports this paper.

\section{Sociodemographic and resource characteristics}

Participants self-reported sociodemographic and resource characteristics during measurement sessions. Self-reported age (65-69 years; 70-74 years; 75-79 years; $80+$ years), race (White; non-White), education level (completed secondary school or less; some trade/technical school or college through completed trade/technical school or college diploma; some university or higher), marital status (single; married; widowed, separated or divorced), cohabitation with someone, dog ownership, current valid driver's license, and vehicle at their disposal were assessed via questionnaire. We assessed neighborhood walkability using Street Smart Walk Score, a single measure that accounts for distance to popular amenities and street design (www.walkscore.com). We categorized walkability based on cut-off categories as recommended by designers of Street Smart Walk Score (car dependent 0-49, somewhat walkable 50-69, very walkable 70-89, walker's paradise 90-100). In-depth description of Walk Score can be found elsewhere [88,89]. Participants also reported how long they lived in their current neighborhood (classified into quartiles: less than 2 years; between 2 and up to 6 years;

\section{Three Types of Activity Spaces}

Standard Deviation Ellipse

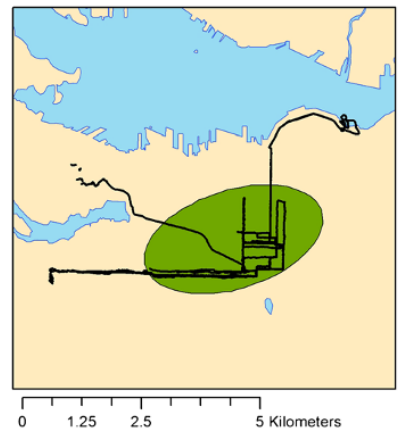

Legend

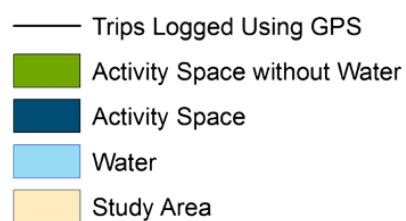

Figure 3 Example of three types of activity spaces.
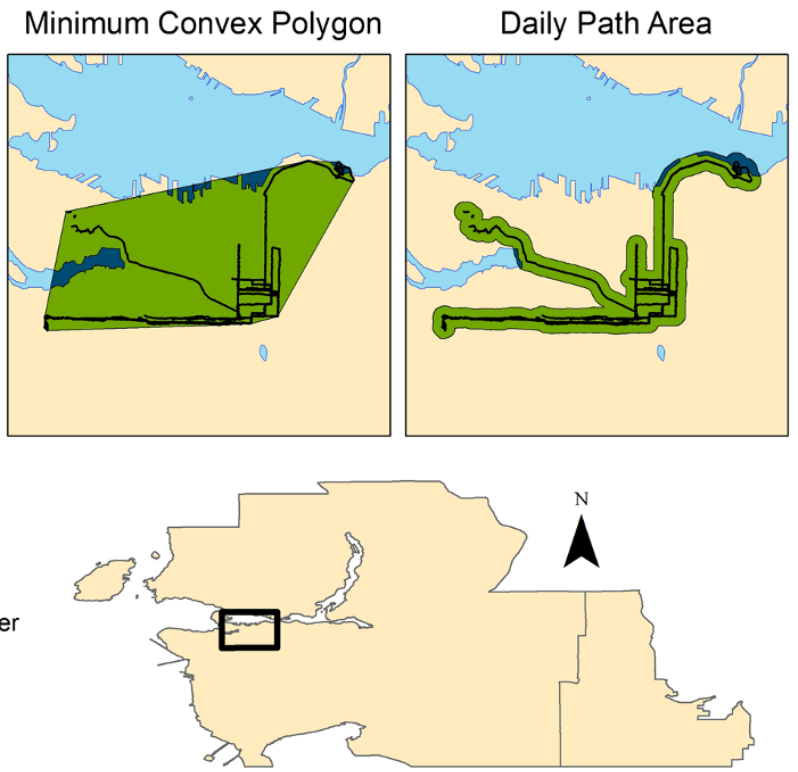
between 6 and up to 9 years; more than 9 years), whether people in their lives offered support related to going outside in their neighborhood (no or don't know; yes, people that offer physical support (drive places); yes, people that offer social support/companionship; yes, people that offer both physical and social support), how much they liked to walk outside (not at all, not much or neutral; somewhat; very much), how confident they were walking in their neighborhood (not at all, not much or neutral; somewhat; very much), and whether they had any falls in the past 6 months or used a mobility aid for walking.

\section{Statistical methods}

We examined the correlation between each of the three activity spaces using Spearman's and Pearson's correlation coefficients $(\rho)$ for area and compactness, respectively. We describe area using medians and IQR due to nonnormal distribution. We describe compactness as mean and SD. We used one-way Analysis of Variance (ANOVA), Kruskal-Wallis non-parametric one-way ANOVA or Wilcoxon Rank Sum test to test for differences in area and compactness of each activity space across sociodemographic and resource categories, as appropriate. We used linear Ordinary Least Squares (OLS) regression models, to assess the associations between sociodemographic and resource characteristics of participants and log-transformed area or non-transformed compactness of activity spaces after adjustment for other potential variables. Variables were included in the simultaneous model based on apriori hypothesis (sex, age, education) or if they were associated $(\mathrm{p}<0.1)$ to dependent variables in bivariate analyses. To enhance interpretability, results from regression models for area have been retransformed and presented as percentage differences. We conducted all statistical analyses using SAS software, Version 9.3 (SAS Institute Inc., Cary, NC, USA).

\section{Additional file}

Additional file 1: We have provided a generic python script to enable others to easily create activity spaces using their own GPS data: Activity_Space_Processing_TEMPLATE_supplement.py.

\section{Abbreviations}

ANOVA: Analysis of variance; DPA: Daily path area; GPS: Global positioning system; IQR: Interquartile range; MCP: Minimum convex polygon; SAFER: Shelter aid for elderly renters; SenTra: Senior tracking; SD: Standard deviation; SDE: Standard deviation ellipse; WTT: Walk the talk.

\section{Competing interests}

The authors declare that they have no competing interests.

\section{Authors' contributions}

$\mathrm{JH}$ conceived of the study, designed and executed activity space calculations, performed the statistical analyses, and drafted the manuscript MW shaped the conceptualization of activity spaces, supervised the activity space calculations, advised the statistical analyses, and critically revised the manuscript. PC and HM participated in designing and coordinating the Walk
The Talk (WTT) study and critically revised the manuscript to ensure it was relevant to the field of older adult mobility. All authors read and approved the final manuscript.

\section{Acknowledgements}

Ongoing research was funded by the Canadian Institutes of Health Research (CIHR) (Grant \#108607 "Walk the Talk: Transforming the Built Environment to Enhance Mobility in Seniors Team"). The authors thank community partners, BC Housing, and study participants for their valuable collaborations and involvement. The authors graciously acknowledge Anna Chudyk for coding of the travel diaries and Karen Schellenberg, Vivian Chung, Christine Voss and Morgan Schinkel for their contributions to the GPS and accelerometry data processing. The content is solely the responsibility of the authors and does not necessarily represent the official views of the CIHR.

\section{Author details}

${ }^{1}$ Centre for Hip Health and Mobility and Department of Medicine, University of British Columbia, 2635 Laurel Street, Vancouver, British Columbia V5Z 1 M9, Canada. ${ }^{2}$ Carolina Population Center, University of North Carolina at Chapel Hill, 206 West Franklin St, Chapel Hill, NC 27516, USA. ${ }^{3}$ Faculty of Health Sciences, Simon Fraser University, 8888 University Drive, Burnaby, British Columbia V5A 1S6, Canada. ${ }^{4}$ Institute for Social Research, University of Michigan, 426 Thompson Street, Ann Arbor, MI 48104, USA. ${ }^{5}$ Centre for Hip Health and Mobility and Department of Family Practice, University of British Columbia, 2635 Laurel Street, Vancouver, British Columbia V5Z 1 M9, Canada.

Received: 10 October 2014 Accepted: 30 November 2014 Published: 12 December 2014

\section{References}

1. Webber SC, Porter MM, Menec VH: Mobility in older adults: a comprehensive framework. The Gerontologist 2010, 50(4):443-450. doi:10.1093/geront/gnq013.

2. World Health Organization: Global age-Friendly Cities: A Guide. Geneva, Switzerland: World Health Organization; 2007.

3. Alsnih $\mathrm{R}$, Hensher DA: The mobility and accessibility expectations of seniors in an aging population. Transp Res A Policy Pract 2003, 37(10):903-916.

4. Sugiyama T, Thompson CW: Outdoor environments, activity and the well-being of older people: conceptualising environmental support. Environment and Planning A 2007, 39(8):1943.

5. Ziegler F, Schwanen T: 'I like to go out to be energised by different people': an exploratory analysis of mobility and wellbeing in later life. Ageing Soc 2011, 31(05):758-781.

6. Abraham A, Sommerhalder K, Abel T: Landscape and well-being: a scoping study on the health-promoting impact of outdoor environments. Int $J$ Public Health 2010, 55(1):59-69.

7. Spinney JE, Scott DM, Newbold KB: Transport mobility benefits and quality of life: a time-use perspective of elderly Canadians. Transp Policy 2009, 16(1):1-11.

8. Metz D: Mobility of older people and their quality of life. Transp Policy 2000, 7(2):149-152.

9. Paez A, Scott D, Potoglou D, Kanaroglou P, Newbold KB: Elderly mobility: demographic and spatial analysis of trip making in the Hamilton CMA, Canada. Urban Stud 2007, 44(1):123-146.

10. Golob TF, Hensher DA: The trip chaining activity of Sydney residents: a cross-section assessment by age group with a focus on seniors. J Transp Geogr 2007, 15(4):298-312.

11. Scott DM, Newbold KB, Spinney JE, Mercado R, Páez A, Kanaroglou PS: New insights into senior travel behavior: the Canadian experience. Growth Change 2009, 40(1):140-168.

12. Rosenbloom $\mathrm{S}$ : Meeting transportation needs in an aging-friendly community. Generations 2009, 33(2):33-43.

13. Broome K, Worrall L, McKenna K, Boldy D: Priorities for an age-friendly bus system. Can J Aging 2010, 29(03):435-444.

14. Yen $\mathrm{H}$, Michael $\mathrm{YL}$, Perdue L: Neighborhood environment in studies of health of older adults: a systematic review. Am J Prev Med 2009, 37(5):455-463.

15. Baker PS, Bodner EV, Allman RM: Measuring life-space mobility in community-dwelling older adults. J Am Geriatr Soc 2003, 51(11):1610-1614.

16. May D, Nayak U, Isaacs B: The life-space diary: a measure of mobility in old people at home. Disabil Rehabil 1985, 7(4):182-186. 
17. Peel C, Baker PS, Roth DL, Brown CJ, Bodner EV, Allman RM: Assessing mobility in older adults: the UAB study of aging life-space assessment. Phys Ther 2005, 85(10):1008-1019.

18. Crowe M, Andel R, Wadley VG, Okonkwo OC, Sawyer P, Allman RM: Life-space and cognitive decline in a community-based sample of African American and Caucasian older adults. J Gerontol A: Biol Med Sci 2008, 63(11):1241-1245.

19. James BD, Boyle PA, Buchman AS, Barnes LL, Bennett DA: Life space and risk of Alzheimer disease, mild cognitive impairment, and cognitive decline in Old Age. Am J Geriatr Psychiatry 2011, 19(11):961-969.

20. Boyle PA, Buchman AS, Barnes LL, James BD, Bennett DA: Association between life space and risk of mortality in advanced Age. J Am Geriatr Soc 2010, 58(10):1925-1930.

21. Xue Q-L, Fried LP, Glass TA, Laffan A, Chaves PH: Life-space constriction, development of frailty, and the competing risk of mortality the Women's health and aging study I. Am J Epidemio/ 2008, 167(2):240-248

22. Snih SA, Peek KM, Sawyer P, Markides KS, Allman RM, Ottenbacher KJ: Life-space mobility in Mexican Americans aged 75 and older. J Am Geriatr Soc 2012, 60(3):532-537.

23. Byles JE, Leigh L, Vo K, Forder $P$, Curryer C: Life space and mental health: a study of older community-dwelling persons in Australia. Aging Ment Health 2014, 19(2):1-9. doi:10.1080/13607863.2014.917607.

24. Sikder S, Pinjari A: Immobility levels and mobility preferences of the elderly in the united states. Transportation Research Record: Journal of the Transportation Research Board 2012, 2318(-1):137-147.

25. Zeitler E, Buys L: Mobility and out-of-home activities of older people living in suburban environments:'Because I'm a driver, I don't have a problem'. Ageing Soc 2014, 1-24. http://dx.doi.org/10.1017/S0144686X13001086.

26. Shah RC, Maitra K, Barnes LL, James BD, Leurgans S, Bennett DA: Relation of driving status to incident life space constriction in community-dwelling older persons: a prospective cohort study. J Gerontol A: Biol Med Sci 2012, 67(9):984-989.

27. Tung JY, Rose RV, Gammada E, Lam I, Roy EA, Black SE, Poupart P: Measuring life space in older adults with mild-to-moderate Alzheimer's disease using mobile phone GPS. Gerontology 2013, 60(2):154-162.

28. Wan N, Lin G: Life-space characterization from cellular telephone collected GPS data. Comput Environ Urban Syst 2013, 39:63-70.

29. Boissy P, Brière S, Hamel M, Jog M, Speechley M, Karelis A, Frank J, Vincent C, Edwards R, Duval C: Wireless Inertial Measurement Unit With GPS (WIMU-GPS) - Wearable Monitoring Platform for Ecological Assessment of Lifespace and Mobility in Aging and Disease. In Engineering in Medicine and Biology Society, EMBC, 2011 Annual International Conference of the IEEE: 2011. Boston, MA: IEEE; 2011:5815-5819. http://dx.doi.org/10.1109/ IEMBS.2011.6091439.

30. Wan N, Qu W, Whittington J, Witbrodt BC, Henderson MP, Goulding EH, Schenk AK, Bonasera SJ, Lin G: Assessing smart phones for generating life-space indicators. Environ Plann Plann Des 2013, 40(2):350-361.

31. Liddle J, Ireland D, McBride SJ, Brauer SG, Hall LM, Ding H, Karunanithi M, Hodges PW, Theodoros D, Silburn PA: Measuring the lifespace of people with Parkinson's disease using smartphones: proof of principle. JMIR mhealth and whealth 2014, 2(1):e13.

32. Schenk AK, Witbrodt BC, Hoarty CA, Carlson RH Jr, Goulding EH, Potter JF, Bonasera SJ: Cellular telephones measure activity and lifespace in community-dwelling adults: proof of principle. J Am Geriatr Soc 2011, 59(2):345-352.

33. Kerr J, Marshall S, Godbole S, Neukam S, Crist K, Wasilenko K, Golshan S, Buchner D: The relationship between outdoor activity and health in older adults using GPS. Int J Environ Res Publ Health 2012, 9(12):4615-4625.

34. Herrmann SD, Snook EM, Kang M, Scott CB, Mack MG, Dompier TP, Ragan BG: Development and validation of a movement and activity in physical space score as a functional outcome measure. Arch Phys Med Rehabil 2011, 92(10):1652-1658.

35. Rosenberg DE, Huang DL, Simonovich SD, Belza B: Outdoor built environment barriers and facilitators to activity among midlife and older adults with mobility disabilities. The Gerontologist 2013 53(2):268-279. doi:10.1093/geront/gns119.

36. Buys L, Snow S, van Megen K, Miller E: Transportation behaviours of older adults: an investigation into car dependency in urban Australia. Australas J Ageing 2012, 31(3):181-186

37. Wettstein M, Wahl H-W, Diehl MK: A multidimensional view of out-of-home behaviors in cognitively unimpaired older adults: examining differential effects of socio-demographic, cognitive, and health-related predictors. Eur J Ageing 2014, 11(2):141-153.
38. Shoval N, Auslander G, Cohen-Shalom K, Isaacson M, Landau R, Heinik J: What can we learn about the mobility of the elderly in the GPS era? J Transp Geogr 2010, 18(5):603-612.

39. Kaspar R, Oswald F, Wahl H-W, Voss E, Wettstein M: Daily mood and Out-of-home mobility in older adults does cognitive impairment matter? J Appl Gerontol 2012, doi:10.1177/0733464812466290.

40. Wahl H-W, Wettstein M, Shoval N, Oswald F, Kaspar R, Issacson M, Voss E, Auslander G, Heinik J: Interplay of cognitive and motivational resources for out-of-home behavior in a sample of cognitively heterogeneous older adults: findings of the SenTra project. J Gerontol Ser B Psychol Sci Soc Sci 2013, 68(5):691-702. doi:10.1093/geronb/gbs106.

41. Oswald F, Wahl H-W, Voss E, Schilling O, Freytag T, Auslander G, Shoval N, Heinik J, Landau R: The Use of tracking technologies for the analysis of outdoor mobility in the face of dementia: first steps into a project and some illustrative findings from Germany. Journal of Housing For the Elderly 2010, 24(1):55-73.

42. Wettstein M, Wahl H-W, Shoval N, Oswald F, Voss E, Seidl U, Frölich L, Auslander G, Heinik J, Landau R: Out-of-home behavior and cognitive impairment in older adults: findings of the SenTra project. J App/ Gerontol 2012, doi:10.1177/0733464812459373.

43. Werner S, Auslander GK, Shoval N, Gitlitz T, Landau R, Heinik J: Caregiving burden and out-of-home mobility of cognitively impaired care-recipients based on GPS tracking. Int Psychogeriatr 2012, 24(11):1836-1845.

44. Wettstein M, Wahl H-W, Shoval N, Auslander G, Oswald F, Heinik J: Identifying mobility types in cognitively heterogeneous older adults based on GPS-tracking: what discriminates best? J App/ Gerontol 2013, doi:10.1177/0733464813512897.

45. Wettstein M, Wahl H-W, Shoval N, Auslander G, Oswald F, Heinik J: Cognitive status moderates the relationship between out-of-home behavior (OOHB), environmental mastery and affect. Arch Gerontol Geriatr 2014, 59(1):113-121.

46. Shoval N, Wahl H-W, Auslander G, Isaacson M, Oswald F, Edry T, Landau R, Heinik J: Use of the global positioning system to measure the out-ofhome mobility of older adults with differing cognitive functioning. Ageing Soc 2011, 31(05):849-869.

47. Shoval N, Auslander GK, Freytag T, Landau R, Oswald F, Seidl U, Wahl H-W Werner S, Heinik J: The use of advanced tracking technologies for the analysis of mobility in Alzheimer's disease and related cognitive diseases. BMC Geriatr 2008, 8(1):7.

48. Perchoux C, Chaix B, Cummins S, Kestens Y: Conceptualization and measurement of environmental exposure in epidemiology: accounting for activity space related to daily mobility. Health \& place 2013, 21:86-93.

49. Sherman JE, Spencer J, Preisser JS, Gesler WM, Arcury TA: A suite of methods for representing activity space in a healthcare accessibility study. Int J Health Geogr 2005, 4(1):24.

50. Zenk SN, Schulz AJ, Matthews SA, Odoms-Young A, Wilbur J, Wegrzyn L, Gibbs K, Braunschweig C, Stokes C: Activity space environment and dietary and physical activity behaviors: a pilot study. Health Place 2011, 17(5):1150-1161.

51. Matthews SA, Yang T-C: Spatial polygamy and contextual exposures (SPACEs): promoting activity space approaches in research on place and health. Am Behav Sci 2013, 57(8):1057-1081. doi:10.1177/ 0002764213487345.

52. Starnes HA: Tests and development of perceived and objective built environment measures for physical activity research. Purdue (West Lafayette, Indiana): 2012. http://docs.lib.purdue.edu/dissertations/AAl3544536/.

53. Manaugh K, El-Geneidy A: What makes travel'local': Defining and understanding local travel behaviour. Journal of Transport and Land Use 2012, 5(3):15-17. doi:10.5198/jtlu.v5i3.300.

54. Frank JS, Patla AE: Balance and mobility challenges in older adults: Implications for preserving community mobility. Am J Prev Med 2003, 25(3, Supplement 2):157-163.

55. Harding C, Patterson Z, Miranda-Moreno L: Activity Space Geometry and its Effect on Mode Choice. In 92nd Annual Meeting of the Transportation Research Board, Washington, DC: 2013. ; 2013.

56. Prins RG, Pierik F, Etman A, Sterkenburg RP, Kamphuis CBM, van Lenthe FJ: How many walking and cycling trips made by elderly are beyond commonly used buffer sizes: Results from a GPS study. Health Place 2014, 27:127-133

57. Kwan M-P: How GIS can help address the uncertain geographic context problem in social science research. Ann GIS 2012, 18(4):245-255. 
58. Brownson RC, Hoehner CM, Day K, Forsyth A, Sallis JF: Measuring the built environment for physical activity: state of the science. Am J Prev Med 2009, 36(4):S99-S123. e112

59. Chaix B: Geographic life environments and coronary heart disease: a literature review, theoretical contributions, methodological updates, and a research agenda. Annu Rev Public Health 2009, 30:81-105.

60. Chaix B, Kestens Y, Perchoux C, Karusisi N, Merlo J, Labadi K: An interactive mapping tool to assess individual mobility patterns in neighborhood studies. Am J Prev Med 2012, 43(4):440-450.

61. Cummins S: Commentary: investigating neighbourhood effects on health-avoiding the 'local trap'. Int J Epidemiol 2007, 36(2):355-357.

62. Rainham D, McDowell I, Krewski D, Sawada M: Conceptualizing the healthscape: contributions of time geography, location technologies and spatial ecology to place and health research. Soc Sci Med 2010, 70(5):668-676.

63. Krenn PJ, Titze S, Oja P, Jones A, Ogilvie D: Use of global positioning systems to study physical activity and the environment: a systematic review. Am J Prev Med 2011, 41(5):508-515. doi:10.1016/j.amepre.2011.06.046.

64. Oliver M, Duncan M, Badland H, Duncan J, MacRae D: Global positioning systems in physical activity research: past, present, and future. http://discovery.ucl.ac.uk/1320088/.

65. Vine D, Buys $L$, Aird R: The use of amenities in high density neighbourhoods by older urban Australian residents. Landsc Urban Plan 2012, 107(2):159-171.

66. Rodríguez DA, Cho G-H, Evenson KR, Conway TL, Cohen D, Ghosh-Dastidar B, Pickrel JL, Veblen-Mortenson S, Lytle LA: Out and about: association of the built environment with physical activity behaviors of adolescent females. Health Place 2012, 18(1):55-62.

67. Boruff BJ, Nathan A, Nijënstein S: Using GPS technology to (re)-examine operational definitions of 'neighbourhood'in place-based health research. Int J Health Geogr 2012, 11(1):22.

68. Worton B: A review of models of home range for animal movement. Ecol Model 1987, 38(3):277-298.

69. Rosso AL, Auchincloss AH, Michael YL: The urban built environment and mobility in older adults: a comprehensive review. J Aging Res 2011 2011: http://dx.doi.org/10.4061/2011/816106

70. Clarke P, Ailshire JA, Bader M, Morenoff JD, House JS: Mobility disability and the urban built environment. Am J Epidemiol 2008, 168(5):506-513.

71. Clarke P, Ailshire JA, Lantz P: Urban built environments and trajectories of mobility disability: findings from a national sample of community-dwelling American adults (1986-2001). Soc Sci Med 2009, 69(6):964-970

72. Zenk SN, Schulz AJ, Odoms-Young A, Wilbur J, Matthews SA, Gamboa C, Wegrzyn LR, Hobson S, Stokes C: Feasibility of using global positioning systems (GPS) with diverse urban adults: Before and after data on perceived acceptability, barriers, and ease of use. J Phys Act Health 2012, 9(7):924

73. Auslander GK, Werner S, Shoval N, Isaacson M, Landau R, Heinik J: Cooperation with complex research protocols: the use of global positioning systems with cognitively impaired elders-a preliminary report. Life 2010, 17(5.65):15-45.

74. Chaix B, Meline J, Duncan S, Merrien C, Karusisi N, Perchoux C, Lewin A, Labadi $K$, Kestens Y: GPS tracking in neighborhood and health studies: a step forward for environmental exposure assessment, a step backward for causal inference? Health Place 2013, 21:46-51.

75. Chudyk AM, Winters M, Moniruzzaman M, Ashe MC, Sims Gould J, McKay H: Destinations matter: the association between where older adults live and their travel behavior. Journal of Transport and Health. In Press.

76. Kerr J, Duncan S, Schipperjin J: Using global positioning systems in health research: a practical approach to data collection and processing. Am J Prev Med 2011, 41(5):532-540.

77. Thierry $B$, Chaix B, Kestens $Y$ : Detecting activity locations from raw GPS data: a novel kernel-based algorithm. Int J Health Geogr 2013, 12(1):14.

78. Rodriguez D, Cho G-H, Elder J, Conway T, Evenson KR, Ghosh-Dastidar B, Shay E, Cohen DA, Veblen-Mortenson S, Pickrell J: Identifying walking trips from GPS and accelerometer data in adolescent females. J Phys Act Health 2012, 9(3):421.

79. Ellis K, Godbole S, Marshall S, Lanckriet G, Staudenmayer J, Kerr J: Identifying active travel behaviors in challenging environments using GPS, accelerometers, and machine learning algorithms. Frontiers in public health 2014, 2:36. doi:10.3389/fpubh.2014.00036.
80. Hwang S, Hanke T, Evans C: Automated Extraction of Community Mobility Measures from GPS Stream Data Using Temporal DBSCAN. In Computational Science and Its Applications-ICCSA 2013. Springer; 2013:86-98. http://link.springer.com/chapter/10.1007/978-3-642-396434_7. ISBN 978- 3-642-39642-7.

81. Voss C, Winters M, Frazer AD, McKay HA: They go straight home-don't they? Using global positioning systems to assess adolescent school-travel patterns. Journal of Transport \& Health 2014, doi:10.1016/j.jth.2014.09.013.

82. Panter J, Costa S, Dalton A, Jones A, Ogilvie D: Development of methods to objectively identify time spent using active and motorised modes of travel to work: how do self-reported measures compare? Int J Behav Nutr Phys Act 2014, 11(1):116.

83. Newsome TH, Walcott WA, Smith PD: Urban activity spaces: Illustrations and application of a conceptual model for integrating the time and space dimensions. Transportation 1998, 25(4):357-377.

84. Yuill RS: The standard deviational ellipse; an updated tool for spatial description. Geografiska Annaler Series B Human Geography 1971, 53(1):1971. doi:10.2307/490885.

85. Lefever DW: Measuring geographic concentration by means of the standard deviational ellipse. Am J Socio/ 1926, 32(1):88-94. http://www. jstor.org/stable/2765249.

86. Fan Y, Khattak AJ: Urban form, individual spatial footprints, and travel: examination of space-use behavior. Transportation Res Record: $J$ Transportation Res Board 2008, 2082(1):98-106.

87. Kwan MP: Gender and individual access to urban opportunities: a study using space-time measures. Prof Geogr 1999, 51(2):210-227.

88. Hirsch JA, Diez Roux AV, Moore KA, Evenson KR, Rodriguez DA: Change in walking and body mass index following residential relocation: the multi-ethnic study of atherosclerosis. Am J Public Health 2014, 104(3):e49-e56.

89. Hirsch JA, Moore KA, Evenson KR, Rodriguez DA, Roux AVD: Walk score ${ }^{\circledast}$ and transit score ${ }^{\circledR}$ and walking in the multi-ethnic study of atherosclerosis. Am J Prev Med 2013, 45(2):158-166.

doi:10.1186/1476-072X-13-51

Cite this article as: Hirsch et al:: Generating GPS activity spaces that shed light upon the mobility habits of older adults: a descriptive analysis. International Journal of Health Geographics 2014 13:51.

\section{Submit your next manuscript to BioMed Central and take full advantage of:}

- Convenient online submission

- Thorough peer review

- No space constraints or color figure charges

- Immediate publication on acceptance

- Inclusion in PubMed, CAS, Scopus and Google Scholar

- Research which is freely available for redistribution 